\title{
POSSIBILITY OF COVID-19 REINFECTION WITH CLINICAL MANIFESTATION OF STROKE: A CASE REPORT
}

Septy Aulia Rahmy ${ }^{1}$, Eko Arisetijono ${ }^{2}$, Yuyun Yueniwati ${ }^{3}$.

\author{
${ }^{1}$ Resident of Neurology Departement of Universitas Brawijaya Malang. \\ ${ }^{2}$ Neurologist of Neurology Departement of Universitas Brawijaya Malang. \\ ${ }^{3}$ Radiologist of Radiology Departement of Brawijaya University Malang.
}

\section{*Corresponding author:}

Dr. Septy Aulia Rahmy, Neurology Department, Saiful Anwar General Hospital, Malang, East Java, Indonesia. E-mail: septy_aulia@student.ub.ac.id

DOI: https://doi.org/10.32896/cvns.v3n2.9-15

Published: 30.06 .2021

\begin{abstract}
Background: SARS-CoV-2 virus was first detected in December 2019 and became pandemic. It can spread from the respiratory to the central nervous system due to its neuroinvasive abilities. The information on SARS-CoV-2 recurrence or reinfection is still limited. We reported COVID-19 with stroke manifestation and a history of positive COVID-19, possibly reinfection of the disease.

Case presentation: Male, 55-years old, with a medical history of diabetes mellitus, hypertension, and acute coronary syndrome, was first diagnosed with COVID-19 based on his nasopharyngeal swab without any clinical manifestation. The evaluation of his swabs then showed negative results, and he was declared cured of COVID-19. After 13 days, he came to ER with acute onset of slurred speech, leftsided hemiparesis, dysarthria, and left-sided facial drop. His nasopharyngeal swab showed a positive result, and he was diagnosed with COVID-19. His chest radiography was normal, and his head CT scan showed an ischemic brain. He received treatment for stroke and COVID-19 infection. Five days after admission, the patient spontaneously became hypoxic with oxygen saturation $60 \%$, and the patient died due to respiratory failure.
\end{abstract}

Conclusion: We reported the case possibility of COVID-19 reinfection with clinical manifestation of stroke, without any respiratory manifestation of COVID-19.

Keywords: COVID-19, Stroke, Reinfection.

\section{BACKGROUND}

In December 2019, pneumonia caused by severe acute respiratory syndrome coronavirus 2 (SARSCoV-2), identified as Coronavirus Disease (COVID-19), became pandemic, infected millions of people worldwide, and was responsible for many deaths. ${ }^{1}$ Globally, as of Feb 24 2021, there have been 111,762,965 confirmed cases of COVID-19, including 2,479,678 deaths, reported to World Health Organization (WHO $)^{2}$. The patient's symptoms range from asymptomatic to severe. The most prevalent symptoms include fever, cough, and dyspnea. ${ }^{3}$ SARS-CoV-2 virus also can spread from the respiratory to the central nervous system due to its neuroinvasive abilities. Some patients with COVID-19 were reported to have neurological symptoms, such as anosmia, headache, dizziness, dysgeusia, and impaired consciousness. Ischemic stroke was reported to occur in $0.9 \%$ to $2.3 \%$ of patients with COVID19. ${ }^{4}$ Study by Li Y et al..$^{5}$ reported that ischemic stroke incidence in COVID-19 patients was about $5 \%$ with a mean age of 71 years. These patients 
had risk factors like diabetes, hypertension, coronary artery disease, and previous cerebrovascular disease. The average time from COVID-19 infection to stroke manifestation was 12 days. Lee et al. ${ }^{6}$ conducted a systematic review of twenty-eight studies and a meta-analysis of seven studies and reported the incidence of stroke in COVID-19 was $1.1 \%$. Although stroke incidence among patients with COVID-19 infection is low, patients with COVID-19 infection and who suffered from stroke concurrently with severe infection had a worse prognosis with a higher mortality rate (46.7\%) than if only suffering from COVID-19 and stroke.

The information on SARS-CoV-2 recurrence or reinfection is still limited. A study by Ye et al. ${ }^{7}$ reported 55 patients with a history of COVID-19, five patients $(9 \%)$ had reactivation after discharge from the hospital. The mean time from SARS-CoV-2 reactivation from negative to positive ranged from 4 to 17 days. The reactivation timing can vary depending on 3 points: host status, virologic factors, and immunosuppression type. We reported a case of COVID-19 with stroke manifestation and a history of positive COVID-19 earlier, possibly reinfection of the disease.

\section{CASE REPORT}

Male, 55 years old, came to the emergency department with a medical history of diabetes mellitus on insulin, hypertension treated with ramipril, heart failure treated with bisoprolol, atorvastatin, and history of acute coronary syndrome history of double-J stent (DJ stent) in February 2020. He worked as an administrative officer in the hospital. He was diagnosed with COVID-19 on $26^{\text {th }}$ June based on his nasopharyngeal swab without any clinical manifestation, then isolated himself in his home. His second and third nasopharyngeal swabs on $14^{\text {th }}$ and $15^{\text {th }}$ July then showed negative results, and he was declared cured of COVID-19 infection. On $27^{\text {th }}$ July, he came to emergency departments with acute onset slurred speech, leftsided hemiparesis, dysarthria, and left-sided facial drop two hours before admission when he woke up. The patient denied fevers, cough, nor dyspnea symptoms. There was no history of travels abroad or recent contact with any individuals known to be positive for COVID-19. The patient was fully alert with vital signs: blood pressure of $150 / 60 \mathrm{~mm} \mathrm{Hg}$, pulse of 82 beats per minute, respiratory rate of 20 breaths per minute, body temperature of $36.8^{\circ} \mathrm{C}$, and blood oxygen saturation of $98 \%$ on nasal cannula.

Physical examination revealed slurred speech, left-sided facial droop, and left-sided hemiparesis affecting the upper and lower extremities; there were no visual nor neglected symptoms from the patient. The sensation was intact. Babinski and Chaddock's reflex was positive on the left side. Cardiopulmonary examinations showed no abnormality. The laboratory studies (Table 1) were within normal limits, but his nasopharyngeal swab with positive result, he was diagnosed with COVID-19. He performed chest radiography (Figure 1) with normal result, and his head CT scan (Figure 2) showed ischemic in the right insular lobe and ischemic in the right parietal lobe with senile brain atrophy. Unfortunately, we did not do CT angiography to assess large-vessel occlusion (LVO). He was hospitalized in the high care unit for COVID-19 patients. He received Aspirin for stroke therapy, antibiotics (intravenous Levofloxacin $750 \mathrm{mg}$; Azithromycin $500 \mathrm{mg}$ ), antiviral drugs (Oseltamivir $75 \mathrm{mg}$ bid; Hydroxychloroquine $400 \mathrm{mg}$ ) for COVID-19 therapy with supportive care. On $31^{\text {st }}$ July, five days after admission, the patient spontaneously became hypoxic and somnolence with oxygen saturation 60\%. D-dimer and Fibrinogen results were still normal. We suspected the reason for sudden deterioration was because of his pneumonia COVID-19. The respiratory status still deteriorated, with significant desaturation despite $15 \mathrm{~L}$ of oxygen. We planned to perform endotracheal intubation, but suddenly the patient became apnea fifteen minutes later, and the patient died due to respiratory failure. 


\begin{tabular}{|c|c|c|c|c|c|c|}
\hline & \multirow{2}{*}{$\frac{\text { June } 2020}{26}$} & \multicolumn{4}{|c|}{ July 2020} & \multirow{2}{*}{$\begin{array}{l}\text { Normal } \\
\text { Value }\end{array}$} \\
\hline & & 14 & 15 & 27 & 31 & \\
\hline $\begin{array}{l}\text { Rapid Test SARS } \\
\text { Antibody }\end{array}$ & Reactive & & & Reactive & & \\
\hline Nasopharyngeal swab & $(+)$ & $(-)$ & $(-)$ & $\begin{array}{c}(+) \\
\text { CT Value: } 37.6\end{array}$ & & \\
\hline $\mathrm{Hb}(\mathrm{g} / \mathrm{dL})$ & & & & 13.3 & 13.7 & $13.4-17.7$ \\
\hline Erythrocyte $\left(10^{6} / \mathrm{uL}\right)$ & & & & 4.9 & 5.03 & $4-5.5$ \\
\hline Leukocytes $\left(10^{3} / \mathrm{uL}\right)$ & & & & 8.4 & 12 & $4.3-10.3$ \\
\hline Hematocrit (\%) & & & & 39.3 & 41 & $40-47$ \\
\hline Platelets $\left(10^{3} / \mathrm{uL}\right)$ & & & & 250 & 242 & $142-424$ \\
\hline Blood Glucose (mg/dL) & & & & 174 & & \\
\hline \multicolumn{7}{|l|}{ Blood gas analysis } \\
\hline - $\mathrm{pH}$ & & & & 7.4 & 7.33 & $7.35-7.45$ \\
\hline - $\mathrm{pCO}_{2}(\mathrm{mmHg})$ & & & & 29.5 & 30.3 & $35-45$ \\
\hline - $\mathrm{pO}_{2}(\mathrm{mmHg})$ & & & & 113.5 & 100.3 & $80-100$ \\
\hline - $\mathrm{HCO}_{3}(\mathrm{mmol} / \mathrm{L})$ & & & & 18.2 & 16.2 & $21-28$ \\
\hline - $\mathrm{O}_{2}$ saturation $(\%)$ & & & & 98 & 97.4 & $>95$ \\
\hline CRP (mg/dL) & & & & 0.39 & 4.16 & $<0.3$ \\
\hline Procalcitonin (ng/mL) & & & & $<0.02$ & $<0.02$ & $<0.5$ \\
\hline $\begin{array}{l}\text { Total cholesterol } \\
(\mathrm{mg} / \mathrm{dL})\end{array}$ & & & & 171 & & $60-100$ \\
\hline Triglycerides (mg/dL) & & & & 162 & & $<150$ \\
\hline HDL (mg/dL) & & & & 45 & & $>50$ \\
\hline LDL (mg/dL) & & & & 75 & & $<100$ \\
\hline Fibrinogen (mg/dL) & & & & 301.3 & 396.7 & $154.3-397.8$ \\
\hline D-Dimer (mg/L FEU) & & & & 0.26 & 0.37 & $<0.5$ \\
\hline
\end{tabular}

\section{DISCUSSION}

COVID-19 is Betacoronavirus that binds the ACE-2 receptor to enter the cell. ACE-2 receptors present in multiple organs, including the nervous system, so SARS-CoV-2 can infect neural cells and result in neurological manifestation. ${ }^{8}$ In this case, the patient came to the emergency ward because of acute onset slurred speech, left-sided hemiparesis, dysarthria, and left-sided facial drop, without any manifestation of COVID-19 like fever, cough, dyspnea, nor sore throat; so, we diagnosed him as a stroke attack. Stroke is an uncommon complication in viral CNS infections. Umapathi et al. ${ }^{9}$ reported large vessel strokes in five of 206 SARS-CoV patients in Singapore. In a retrospective study by Avula et al. ${ }^{10}$, four elderly patients with multiple cardiovascular risk factors were diagnosed with COVID-19 developed stroke. Similarly, Guo et al. ${ }^{11}$ reported five stroke cases with positive COVID-19 who had vascular risk factors, including dyslipidemia, diabetes, and hypertension. It is proven that COVID-19 infection is related to cardiovascular 
comorbidities, such as hypertension, diabetes mellitus, and dyslipidemia.

The pathophysiology of stroke following COVID-19 infection is still unclear and debatable. Three mechanisms seem to be responsible for the occurrence of ischemic strokes in COVID-19. These include (1) hypercoagulable state, (2) vasculitis, and (3) cardiomyopathy. It suggested that the virus's invasion triggers the activation of complement systems in vascular endothelium, which initiates the thrombotic process and inflammatory cascades. Vessels are also inflamed by the direct effect of SARS-CoV-2 on the ACE-2 receptors in vascular endothelium and by a systemic immune response to the pathogen called a cytokine storm. In addition, there is increased cardiac stress due to respiratory failure and hypoxemia from the infection, leading to stress cardiomyopathy. ${ }^{11}$

ACE-2 receptors are the primary entry for SARS-Cov-2 infection. Another hypothesis tries to explain the entry of SARS-CoV-2 into the nervous system, including direct injury to the blood and blood-brain barrier, immune-related injury, and hypoxic injury. ${ }^{12}$ SARS-CoV-2 increases the risk of arterial thrombosis with acute ischemic stroke by induced hypercoagulable state and direct virus invasion and immune-mediated neuronal damage. SARS-CoV-2 can penetrate to the central nervous system via the hematogenous or retrograde neuronal route and activating the neuroimmune system making cytokine storm and induces a viral vasculopathy. ${ }^{13}$

In our case, the patient had comorbidities correlated with stroke accidents, namely diabetes mellitus, hypertension, and a history of coronary syndrome. WHO states that the elderly whose underlying medical conditions are at higher risk of developing severe COVID-19 disease. Diabetes is one of the severe comorbidities linked to the severity of coronavirus infections. Based on the global region, $20-50 \%$ of COVID-19 pandemic patients had diabetes. ${ }^{14}$ Guan et al. ${ }^{14,15}$ showed 173 of 1099 patients with COVID-19 in China had severe disease with comorbidities, in which $16.2 \%$ were diabetes mellitus. Hypertension patients in COVID-19 are also at high mortality risk. A systematic review and meta-analysis from Zuin et al. ${ }^{16}$ showed that COVID-19 patients with hypertension have a significantly higher mortality risk. Hypertension and diabetes are proven associated with a higher risk of respiratory infection and an indicator of COVID-19 severity. $\mathrm{Li}$ et al. ${ }^{17}$ reported a meta-analysis from six published studies from China; from 1527 patients with COVID-19, the most common comorbid conditions include diabetes $(9.7 \%)$, cardiovascular disease (16.4\%), and hypertension (17.1\%). Poor outcomes in COVID-19 patients have been reported to be associated with vascular risk factors such as coronary artery disease, hypertension, and diabetes mellitus. It postulated that the SARSCoV-2 virus causing cytokine storm through ACE-2 receptor binding leads to a hypercoagulable state and increasing incidence of vascular thromboses in patients with COVID$19 .{ }^{18,19}$

Reinfection can be defined as recurrent clinical symptoms compatible with COVID-19, accompanied by a positive PCR test (CT value $<35$ ), more than 90 days after the onset of primary infection, supported by close contact exposure, and no evidence of another infection. In the presence of significant exposure (epidemiological risk factors), if clinical symptoms from the first episode resolve and two PCR tests are negative before the new episode, reinfection should be considered during the first 90 days. Meanwhile, recurrence or relapse is defined as recurrent clinical symptoms compatible with COVID-19 by the absence of epidemiological exposure and accompanied by positive or persisting PCR within 90 days of primary infection. ${ }^{20}$

In this case, the patient has been diagnosed with pneumonia COVID-19 infection on $26^{\text {th }}$ June and performing a nasopharyngeal swab twice $\left(14^{\text {th }}\right.$ and $15^{\text {th }}$ July) with a negative result. However, he became positive again after one month from his positive result with clinical manifestation of stroke but without any clinical manifestation of COVID-19. A study by Ye et al. ${ }^{7}$ stated that the meantime from SARS-CoV-2 reactivation from negative to positive ranged from 4 to 17 days. In this case, the patient became positive again 13 days from his negative result or 45 days after the onset of primary infection with a CT value of 37.6. We could not know about environmental exposure from this patient, and he used to work in the hospital. Thus, we considered this patient as reinfection from the definition of reinfection in the 
presence of significant exposure. Unfortunately, we did not perform specific antibody $\operatorname{IgM} / \operatorname{IgG}$ testing to differentiate whether this was reinfection or recurrence of the disease.

\section{CONCLUSION}

We reported the case possibility of COVID-19 reinfection with clinical manifestation acute onset slurred speech, left-sided hemiparesis, dysarthria, and left-sided facial drop, without any manifestation of COVID-19 like fever, cough, dyspnea, nor sore throat, and we diagnosed it as stroke attack. His nasopharyngeal swab result was positive, so we diagnosed him to be infected with COVID-19 infection. The patient has been diagnosed with COVID-19 one month before admission, his second and third nasopharyngeal swabs then showed negative results, and he was cured of COVID-19 infection after that. We hypothesized the manifestation of stroke as a neurological manifestation of COVID-19 without any respiratory manifestation and possibly reinfection of COVID-19. Unfortunately, we did not perform specific antibody $\operatorname{IgM} / \operatorname{IgG}$ testing to differentiate whether this was the disease's reinfection or recurrence.

\section{FIGURE LEGENDS}

Figure 1. Chest Radiography showed normal.

Figure 2. Head CTScan showed ischemic in the right insular lobe and ischemic in the right parietal lobe with senile brain atrophy.

\section{CONSENT FOR PUBLICATION}

Written informed consent was obtained from the patient for publication of this case and any accompanying images. A copy of the written consent is available for review.

\section{CONFLICT OF INTEREST}

The authors declare that they have no conflict of interest.

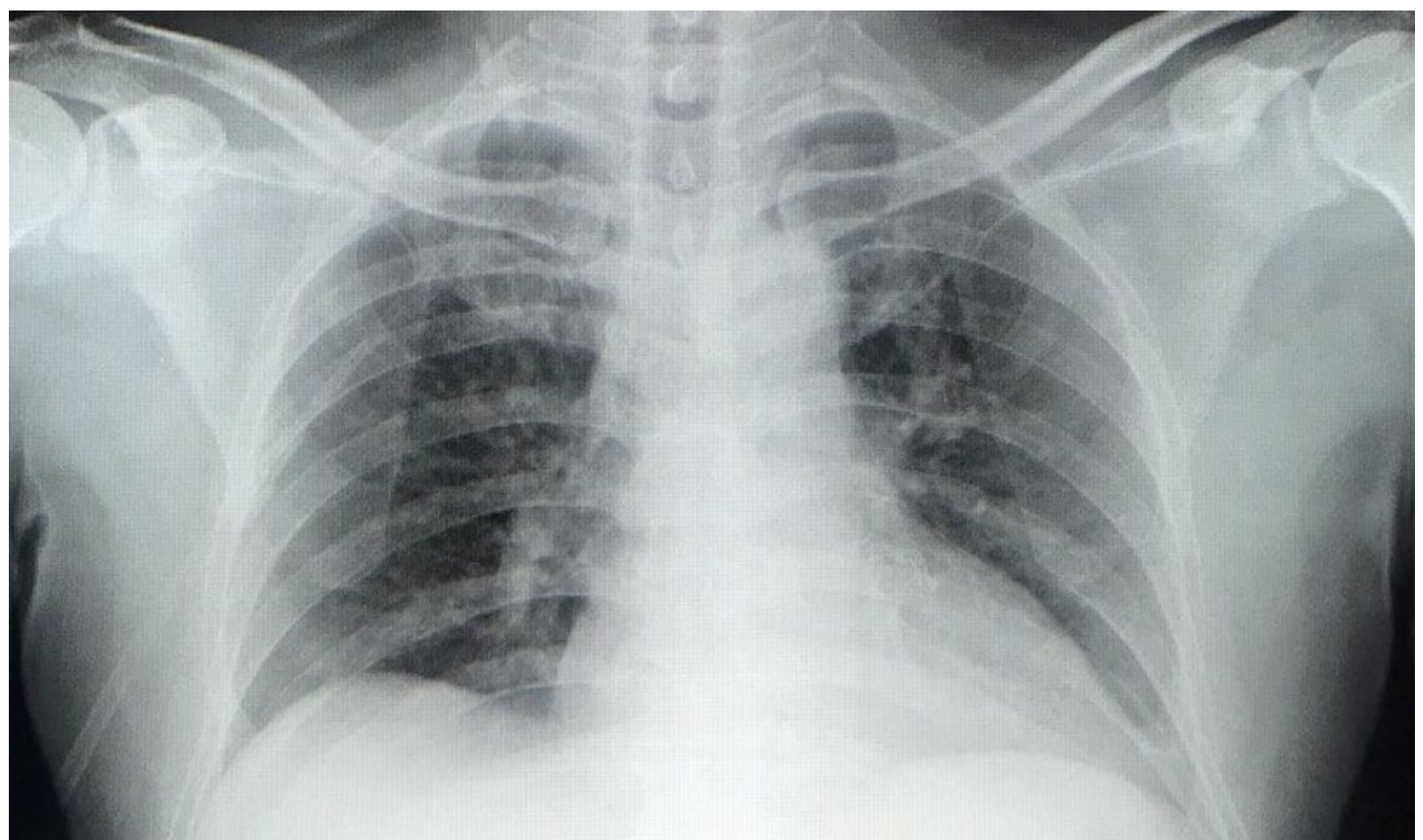

Figure 1 

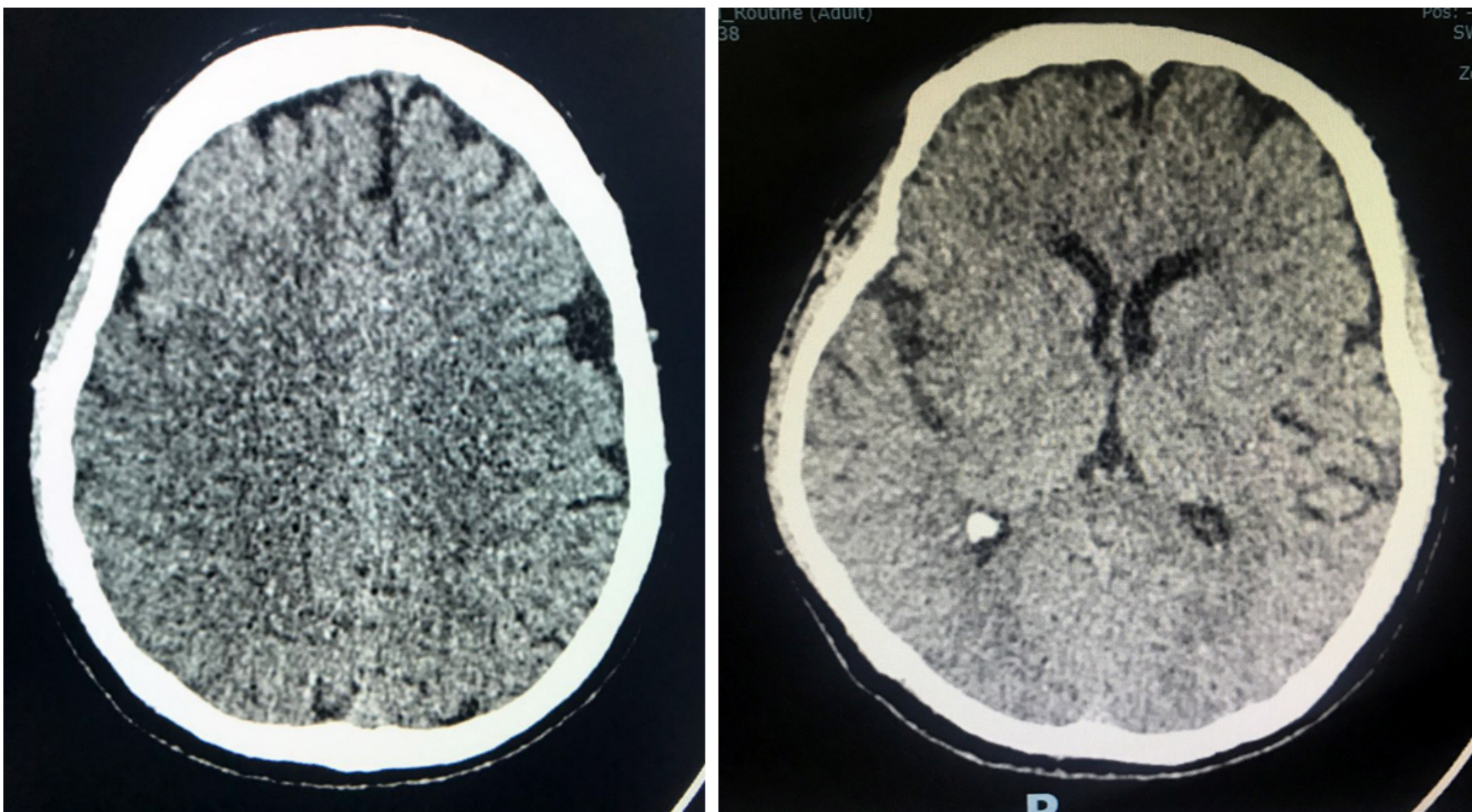

Figure 2

\section{REFERENCES}

1. Zhu N, Zhang D, Wang W, Li X, Yang B, Song J, Zhao X, Huang B, Shi W, Lu R, Niu $\mathrm{P}$. A novel coronavirus from patients with pneumonia in China, 2019. New England journal of medicine. 2020 Jan 24.

2. WHO Coronavirus Disease (COVID-19) Dashboard. 2020.

https://covid19.who.int/?gclid=CjwKCAjwn K36BRBVEiwAsMT8WHbP7GaekySoul5Q dEj08Rudg7EKcqkMORKGrndoj7uGwYYip i9FxoC6QkQAvD_BwE. Accessed Feb 25 2021.

3. Pleasure SJ, Green AJ, Josephson SA. The spectrum of neurologic disease in the severe acute respiratory syndrome coronavirus 2 pandemic infection: neurologists move to the frontlines. JAMA neurology. 2020 Jun 1;77(6):679-80.

4. Mao L, Jin H, Wang M, Hu Y, Chen S, He Q, et al. Neurologic Manifestations of Hospitalized Patients With Coronavirus Disease 2019 in Wuhan, China [published online of print, 2020 10th April]. JAMA Neurol. 2020;e201127. doi:10.1001/JAMA Neurol.2020.1127.

5. Li, Y., Wang, M., Zhou, Y., Chang, J., Xian, Y., Mao, L., Hong, C., Chen, S., Wang, Y.,
Wang, H., and Li, M., 2020. Acute cerebrovascular disease following COVID19: a single-center, retrospective, observational study.

6. Lee, K.W., Khan, A.H.K.Y., Ching, S.M., Chia, P.K., Loh, W.C., Rashid, A.M.I.A., Baharin, J., Mat, L.N.I., Sulaiman, W.A.W., Devaraj, N.K. and Sivaratnam, D., 2020. Stroke and Novel Coronavirus Infection in Humans: A Systematic Review and MetaAnalysis. Frontiers in neurology, 11.

7. Ye, G., Pan, Z., Pan, Y., Deng, Q., Chen, L., Li, J., Li, Y., and Wang, X., 2020. Clinical characteristics of severe acute respiratory syndrome coronavirus two reactivation. Journal of Infection.

8. Nadji, S.A., Sarhangipor, K.A., Shari*Razavi, A. and Baziborun, M., 2020. COVID19 infection recurrence presented with meningoencephalitis. New Microbes and New Infections, p.100732.

9. T. Umapathi, et al., Large artery ischaemic stroke in severe acute respiratory syndrome (SARS), J. Neurol. 251 (10) (2004) 12271231.

10. A. Avula et al., COVID-19 presenting as stroke, Brain Behav. Immun. (2020). 
11. Spence, J.D., de Freitas, G.R., Pettigrew, L.C., Ay, H., Liebeskind, D.S., Kase, C.S., Del Brutto, O.H., Hankey, G.J. and Venketasubramanian, N., 2020. Mechanisms of Stroke in COVID-19. Cerebrovascular Diseases, pp.1-8.

12. Stereo, L., Zorec, R., Verkhratsky, A., 2020. Neuroinfection may contribute to the pathophysiology and clinical manifestations of COVID-19. Acta Physiol. (Oxf.), e13473.

13. M.A. Nagel, R. Mahalingam, R.J. Cohrs, D. Gilden, Virus vasculopathy and stroke: an under-recognized cause and treatment target, Infect. Disord. Drug Targets 10 (2010) 105111.

14. Yueniwati Y, Wangsadjaja C, Yulidani I, Rianawati S, Al Rasyid H. 2018. The role of Brain Magnetic Resonance Imaging (MRI) as an early detector of cognitive impairment. J Neurosci Rural Pract. 9(3):350

15. Bornstein SR, Rubino F, Khunti K, Mingrone G, Hopkins D, et al. Practical recommendations for the management of diabetes in patients with COVID-19. Lancet 2020;8(6):546e50.
https://doi.org/10.1016/S22138587(20)30152-2.

16. Guan W, Ni Z, Hu Y, Liang WH, Ou CQ, et al. Clinical characteristics of coronavirus disease 2019 in China. N Engl J Med 2020;382(18):1708e20. https:// doi.org/10.1056/NEJMoa2002032.

17. Zuin M, Rigatelli G, Zuliani G, Rigatelli A, Mazza A, Roncon L. Arterial hypertension and risk of death in patients with COVID-19 infection: Systematic review and metaanalysis. J Infect 2020;81(1):e84e6. https://doi.org/10.1016/j.jinf.2020.03.059.

18. Li B, Yang J, Zhao F, et al. Prevalence and impact of cardiovascular, metabolic diseases on COVID-19 in China. Clin Res Cardiol 2020; 109: 531-38 CrossRef Medline.

19. Mehta P, McAuley DF, Brown M, et al. COVID-19: consider cytokine storm syndromes and immunosuppression. Lancet 2020;395: 1033-4 CrossRef Medline.

20. Yahav, D., Yelin, D., Eckerle, I., Eberhardt, C.S., Wang, J., Cao, B. and Kaiser, L., 2020. Definitions for COVID-19 reinfection, relapse and PCR re-positivity. Clinical Microbiology and Infection. 